\title{
Preparation and Physicochemical Characterization of
} Natural Phosphate and Kaolin Coatings in Stainless Steel

\author{
R. Najih, ${ }^{1}$ A. Chtaini ${ }^{2, *}$ and H. Oulfajrite ${ }^{2}$ \\ ${ }^{1}$ Laboratoire Valorisation et Sécurité des Produits Agro-Alimentaires, \\ Faculté des Sciences et Techniques de Beni Mellal, Maroc \\ ${ }^{2}$ Equipe d'Electrochimie Moléculaire et Matériaux Inorganiques, \\ Faculté des Sciences et Techniques de Beni Mellal, Maroc
}

\begin{abstract}
The inhibition efficiency of natural phosphate and kaolin systems in controlling corrosion of stainless steel in $\mathrm{HClO}_{4}(0.1 \mathrm{M})$ solution has been evaluated by electrochemical polarization methods, and electrochemical impedance spectroscopy. The electrochemical data show that the corrosion resistance is greatly enhanced after surface modification. The best protection is obtained with natural phosphate. The uniform coatings of phosphate and kaolin on iron substrates were obtained by electro deposition.
\end{abstract}

Keywords: electrodeposition; natural phosphate; kaolin; impedance; polarization; stainless steel.

\section{Introduction}

The corrosion of iron and mild steel is a fundamental academic and industrial concern that has received a considerable amount of attention [1-6]. The use of coating layer mineral compounds is one of the most practical methods of protection from corrosion. Underbody structural components are typically coated to provide a first line of defense against corrosion. Commonly used coatings include conversion, hot melt wax, electrocoat, metallic, organic, autodeposition and powder. Phosphate conversion coatings are employed to enhance paint adhesion, thereby indirectly enhancing corrosion resistance. Hot melt wax coatings are used extensively on underbody structural components to provide corrosion protection, and are usually applied through a dipping process.

\footnotetext{
* Corresponding author. E-mail address: chtainia@yahoo.fr
} 
Electrocoating or E-coating is a process in which electrically charged particles are deposited out of a water suspension to coat a conductive part. The process requires a coating tank in which the conductive metal part is completely immersed. E-coat is widely used to protect underbody structural components from corrosion. Metallic coatings such as zinc, zinc-iron and aluminium, are applied to steel components to inhibit corrosion, using the electroplating, mechanical plating, electroless or hot dipping process. Many underbody structural components are manufactured from sheet steel with a metallic coating [7].

In this work we propose to coat stainless steel surfaces with another material as a natural phosphate and kaolin phases in order to form satisfactory modified electrodes for eventually electrochemical sensor route. To fulfil the purpose of strong adhesion of natural phosphate and kaolin on stainless steel, coating by electrochemical technique is interesting as a simple technique and can be achieved at room temperature.

Based upon the solubility product constant of natural phosphate and kaolin at 25 ${ }^{\circ} \mathrm{C}$, it can be estimated that both the matrices can be easily deposited on stainless steel substrate by electrochemical methods.

\section{Experimental}

\section{Reagent}

A Natural Phosphate (NP) used in this work was obtained in the Khouribga region (Morocco) [8]. Prior to use, this material was treated by techniques involving attrition, sifting, calcinations $\left(900{ }^{\circ} \mathrm{C}\right)$, washing, and recalcination. Kaolin was obtained in the north of Cameroun region.

\section{Sample preparation}

Stainless steel (type 316L) plate was cut into rectangular strips with typical dimensions of $1 \mathrm{~cm}^{2}$. The chemical composition of stainless steel investigated in this work is: (wt.\%) $\mathrm{C} \leq 0.02$, Mo : 3.5-4.5, Cr: 24-26, Ni: 6-8, $\mathrm{N} \geq 0.25$, Fe remainder. Strips were abraded with $\mathrm{SiC}$ paper in successive grades from 400 , 600 up to 1200 grit and then cleaned in distilled water and dried.

The current was maintained by a galvanostat with a function generator. The anode electrode was a platinum wire, and a stainless steel electrode was used as cathode. Then, the electrodes were immersed in a glass chamber containing electrolyte of natural phosphate and/or kaolin gels, and subjected to anodic oxidation by applying $100 \mathrm{~mA}$ for 6 hours.

\section{Modified electrodes characterization}

Scanning Electron Microscopy (SEM) (Jeol JSM-5500 instrument) was used to observe the morphology of samples.

Electrochemical experiments were carried out with a voltalab potentiostat (model PGSTAT 100, Eco Chemie B. V., Utrecht, The Netherlands) driven by the general purpose electrochemical systems data processing software (voltalab master 4 software). The electrochemical cell was configured to work with three- 
electrodes, using NP and/or kaolin modified stainless steel as the working, platinum plate for counter, and saturated calomel (SCE) as reference electrodes. Impedance measurements were made in the frequency range between $10 \mathrm{mHz}$ and $100 \mathrm{KHz}$ with five points per decade at the corrosion potential. A sine wave with $10 \mathrm{mV}$ amplitude was used to perturb the system. The Nyquist diagrams obtained were automatically controlled by computer programs. The electrolytical solution used $\left(0.1 \mathrm{M} \mathrm{HClO}_{4}\right)$ was prepared from distilled and deionised water. All tests were performed at $25^{\circ} \mathrm{C}$.

\section{Results and discussion Modified electrodes}

Fig.1 shows the SEM micrographs of the stainless steel modified respectively with NP and kaolin. It was observed in the both cases that the powder layers exhibited a porous microstructure with micro pores, which were relatively well separated and homogeneously distributed over the surface. The films formed are continued and not disintegrated from substrate surface.
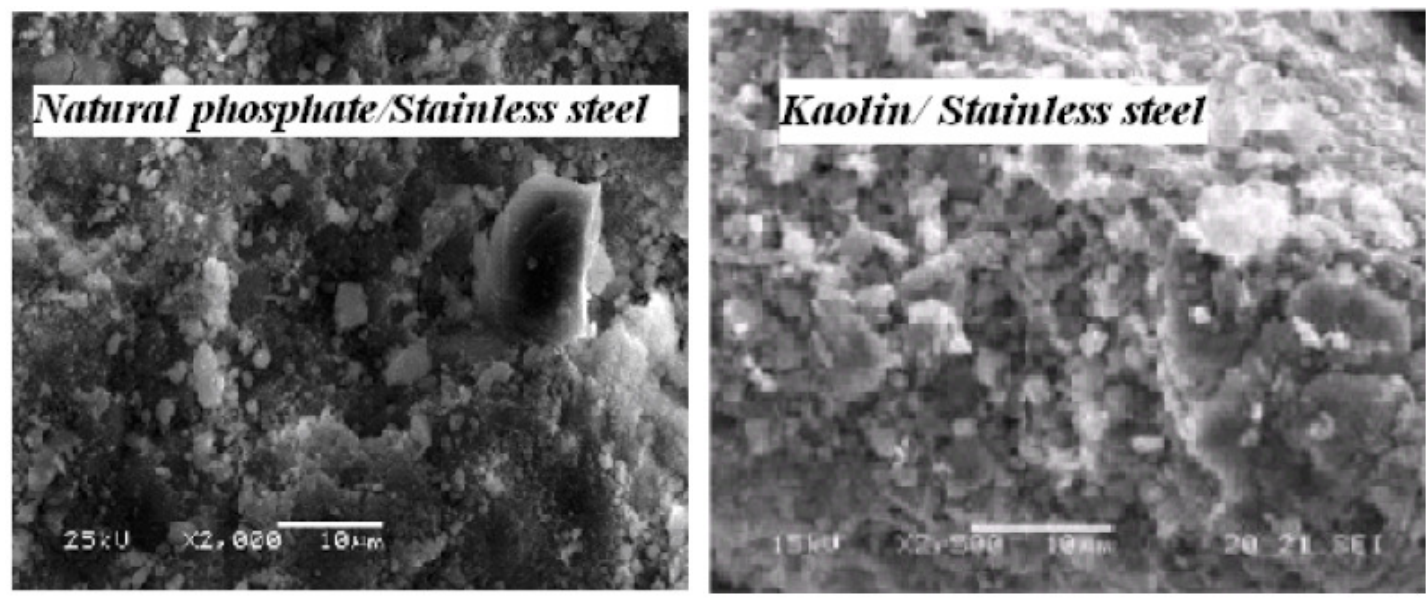

Figure 1. SEM of modified electrodes.

The treatment of NP described above leads to a fraction between $100 \mu \mathrm{m}$ and 400 $\mu \mathrm{m}$ that is rich in phosphate and, as can be seen, the compact NP appearance was evident. The treated $\mathrm{NP}$ has the following chemical composition [9]: $\mathrm{CaO}$ (54.12\%), $\mathrm{P}_{2} \mathrm{O}_{5}(34.24 \%), \mathrm{F}^{-}(3.37 \%), \mathrm{SiO}_{2}(2.42 \%), \mathrm{SO}_{3}(2.21 \%), \mathrm{CO}_{2}(1.13 \%)$, $\mathrm{Na}_{2} \mathrm{O}(0.92 \%), \mathrm{MgO}(0.68 \%), \mathrm{Al}_{2} \mathrm{O}_{3}(0.46 \%), \mathrm{Fe}_{2} \mathrm{O}_{3}(0.36 \%), \mathrm{K}_{2} \mathrm{O}(0.04 \%)$ and several metals in the range of ppm.

The treated kaolin [10] has the following chemical composition [11]: $\mathrm{SiO}_{2}$ (48.01\%), $\mathrm{Al}_{2} \mathrm{O}_{3}(27.41 \%), \mathrm{Fe}_{2} \mathrm{O}_{3}$ (7.34\%), $\mathrm{MnO}$ (0.12\%), $\mathrm{CaO}$ (0.06\%), $\mathrm{MgO}$ $(0.31 \%), \mathrm{K}_{2} \mathrm{O}(0.41 \%), \mathrm{Na}_{2} \mathrm{O}(0.02 \%), \mathrm{S}(0.03 \%)$ and several metals in the range of ppm.

As shown in Fig. 2 on the kaolin/stainless steel electrode, the cyclic voltammograms recorded respectively for stainless steel and kaolin/stainless steel electrodes in $\mathrm{HClO}_{4}(0.1 \mathrm{M})$ solution, demonstrated two different behaviours. In the absence of clay film, the work electrode shows an anodic peak at positive potentials, which probably corresponds to the surface oxidation. In the presence 
of kaolin film, the anodic peak disappears; however, we note the appearance of a redox system at potential value $0 \mathrm{~V}$.

Fig. 3 illustrated the obtained voltammogram, from the NP/stainless steel electrode, in $0.1 \mathrm{M} \mathrm{HClO}_{4}$ solution.

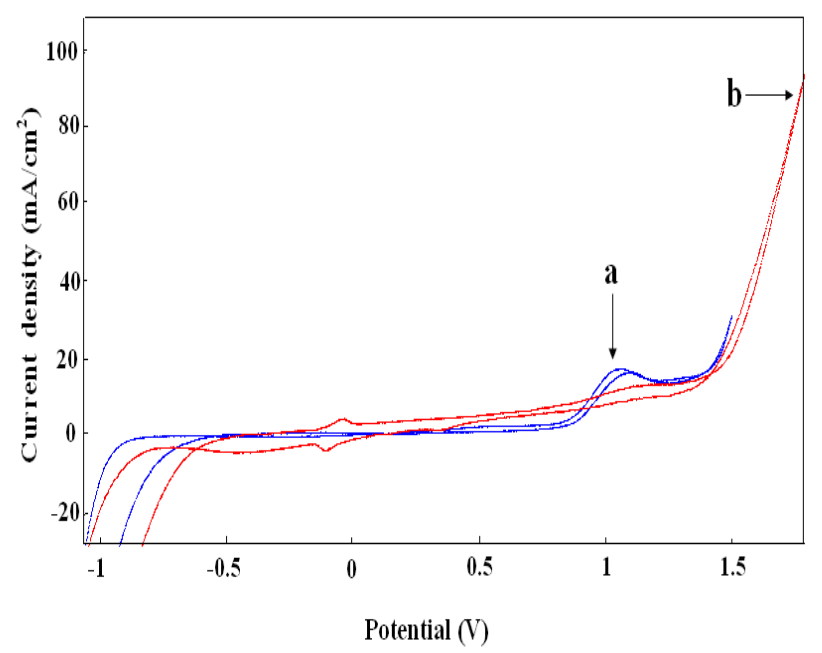

Figure 2. Cyclic voltammograms of-a- stainless steel electrode, -b- kaolin/stainless steel, in $\mathrm{HClO}_{4}(0.1 \mathrm{M})$ at $50 \mathrm{mV} / \mathrm{s}$.

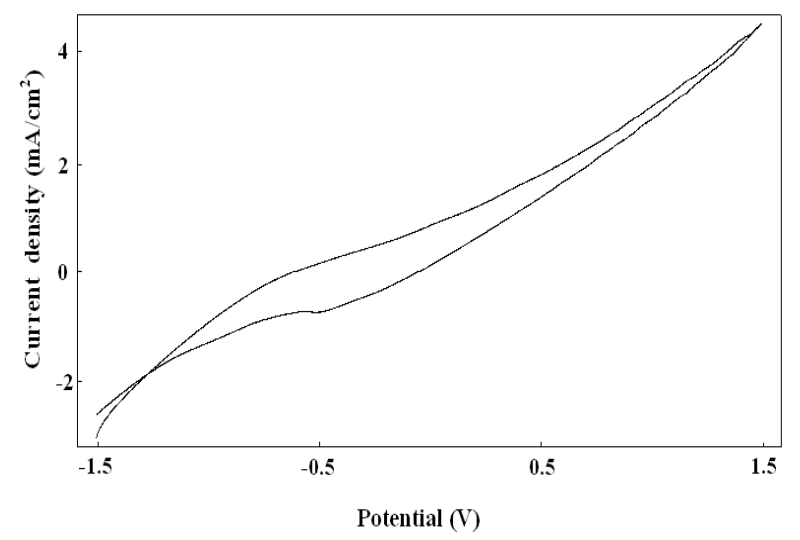

Figure 3. Cyclic voltammogram of $\mathrm{NP} /$ stainless steel electrode in $\mathrm{HClO}_{4}$, at scan rate of $50 \mathrm{mV} / \mathrm{s}$.

The appearance of this voltammogram is different from that obtained by the initial electrode under the same experimental conditions.

Fig. 4 shows the electrochemical impedance curves recorded, respectively, for stainless steel and kaolin/stainless steel electrodes in $0.1 \mathrm{M} \mathrm{HClO}_{4}$ solution. It can be seen that in all the cases the impedance curves are in the form of one semi-circle, indicating one time constant attributed to an electron transfer step. The value of the corresponding polarization resistance increases systematically with the modified electrode. 


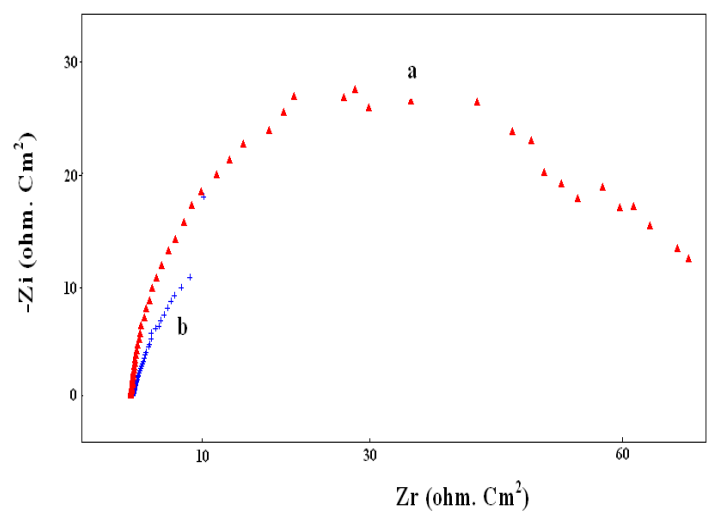

Figure 4. Electrochemical impedance spectroscopy for, a- stainless steel and bkaolin/stainless steel, in $0.1 \mathrm{M} \mathrm{HClO}_{4}$ solution.

Fig. 5 shows the evolution of polarization resistance versus time.

The polarization resistance monitoring is an effective electrochemical method of measuring corrosion. The electrical resistance of any conductor is given by Ohm's Law: $\mathrm{R}=\mathrm{V} / \mathrm{I}$, where $\mathrm{R}$ is the effective instantaneous resistance, Vis the applied voltage, and $\mathrm{I}$ is the instantaneous current between electrodes.

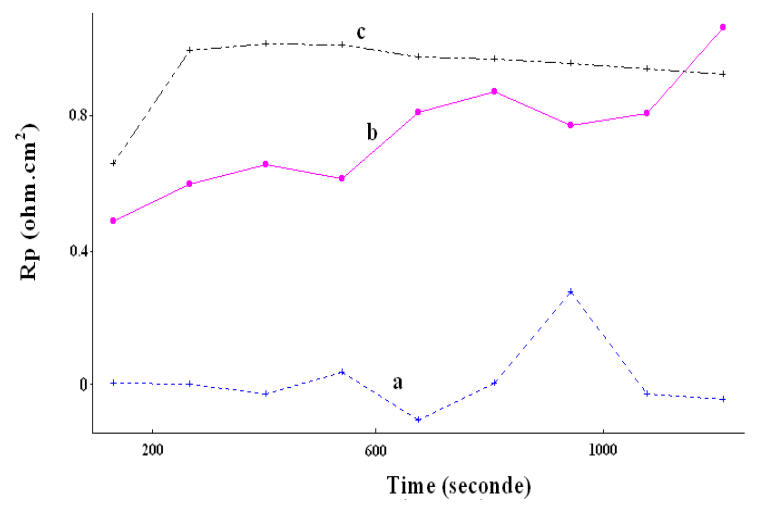

Figure 5. Evolution of polarization resistance with time. a- kaolin/stainless steel, bstainless steel and c- NP/stainless steel.

If the electrodes are corroding at a high rate with the metal ions passing easily into solution, a small potential applied between the electrodes will produce a high current, and there will be low polarization resistance. This corresponds to high corrosion rate.

A strong resistance is recorded by NP/stainless steel. The kaolin deposited onto the substrate undergoes a strong dissolution in the electrolytic medium.

Fig. 6 shows the possibility of developing pitting corrosion in the studied solution. The likelihood of developing a pitting corrosion is higher in the case of stainless steel electrode. The coating electrodes are protected against this type of corrosion. 


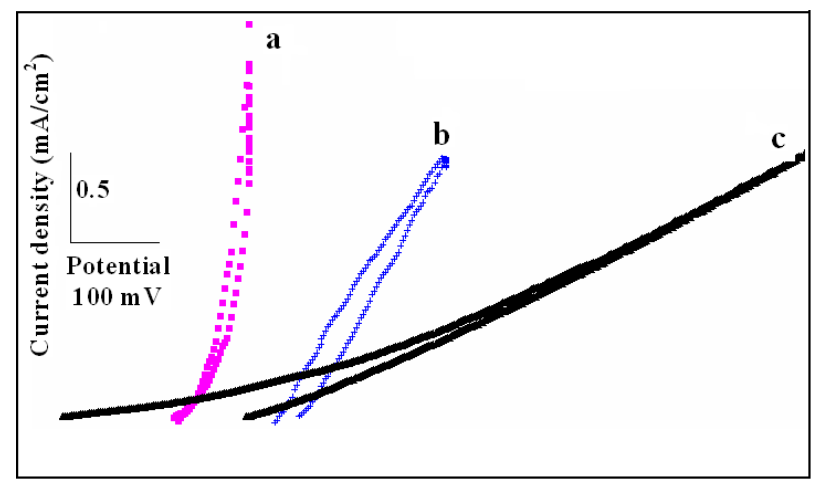

Figure 6. Pitting corrosion possibility for, a- stainless steel, b- kaolin/stainless steel and c- $\mathrm{NP} /$ stainless steel in $0.1 \mathrm{M} \mathrm{HClO}_{4}$ solution.

These results are confirmed by the potentiodynamic polarization behaviour in the Tafel region given in Fig. 7 .

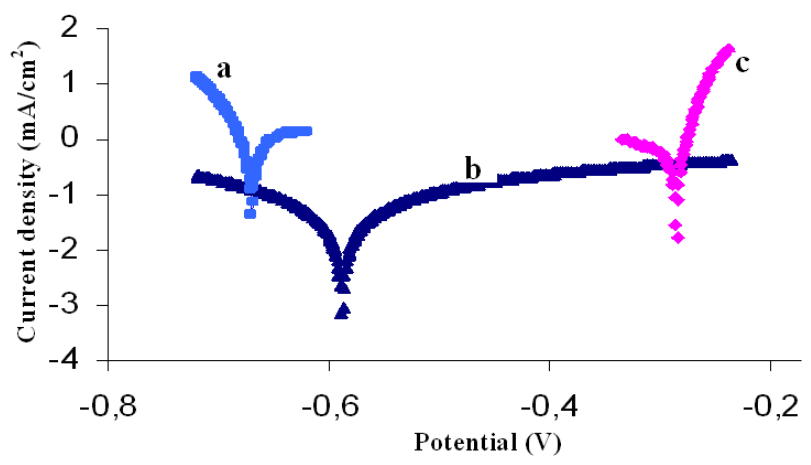

Figure 7. Polarization curves recorded for, a-kaolin/stainless steel, b-NP/stainless steel and c- stainless steel, in $0.1 \mathrm{M} \mathrm{HClO}_{4}$.

The corrosion parameters such as corrosion potential $\left(\mathrm{E}_{\mathrm{corr}}\right)$, corrosion current density $\left(\mathrm{I}_{\text {corr }}\right)$ and Tafel constants $\left(\mathrm{B}_{\mathrm{a}}\right.$ and $\left.\mathrm{B}_{\mathrm{c}}\right)$ derived from these figures are given in Table 1.

Table 1. Summary of electrochemical parameters for the studied electrodes in $0.1 \mathrm{M}$ $\mathrm{HClO}_{4}$ solution.

\begin{tabular}{|c|c|c|c|c|}
\hline Sample & $\mathbf{E}(\mathbf{i}=\mathbf{0})$ & $\mathbf{I c o r r}\left(\mathbf{m A} / \mathbf{c m}^{2}\right)$ & $\mathbf{B a}(\mathbf{m V})$ & $\mathbf{B c}(\mathbf{m V})$ \\
\hline Stainless steel & -140.4 & 0.5439 & 82.9 & -716.1 \\
\hline Kaolin/Stain. ste. & -518.1 & 1.2587 & 3688 & -199 \\
\hline NP/Stain. Ste. & -588 & 0.47 & 2139 & -1186 \\
\hline
\end{tabular}

\section{Conclusion}

It was found that NP and kaolin coatings can provide considerable protection, as well as a physical barrier against corrosion environments in which the metal are 
exposed. The corrosion rate for the NP or kaolin coated steel was significantly lower than that for bare steel.

The corrosion resistance of NP and Kaolin films electro-deposited onto stainless steel has been studied. The following conclusions can be drawn:

1. The films are continuous and also effective.

2. The coating films offer significant protection against steel corrosion in 0.1 $\mathrm{M} \mathrm{HClO}_{4}$ solution.

The NP/stainless steel presents a best corrosion protection.

\section{References}

1. K.R. Adam, M. Antolovich, D.S. Baldwin, P.A. Duckworth, A.J. Leong, I.F. Lindoy, M.M.C. Partin, P.A. Tasker, J. Chem. Soc. Dalton Trans. 48 (1993) 1013. 10.1039/DT9930001013

2. A.J. Blake, G.R. Reid, M. Schroder, J. Chem. Soc. Dalton Trans. 20 (1992) 2987. 10.1039/DT9920002987

3. S. Helliarachi, Y.W. Chain, J. Chem. Technol. 2 (1995) 99.

4. K. Hnini, A. Tounsi, A. Chtaini, Bull. Electrochem. 21 (2005) 163-166.

5. A. ElMhammedi, S. Fadel, A. Chtaini, Bull. Electrochem. 21 (2005) 445449.

6. A. ElMhammedi, L. Kinani, A. Chtaini, L.E. J. Practices and Technologies 11 (2007) 1-6.

7. A guide to corrosion protection. Light Truck Frame Project Team., Michigan 1999.

8. Natural phosphate comes from CERPHOS, Casablanca, Morocco.

9. M.A. El Mhammedi, M. Bakasse, A. Chtaini, J. Hazardous Materials 145 (2007) 1. 10.1016/j.jhazmat.2007.02.054

10. Kaolin comes Northeast of Douala country. Cameroun.

11. Rapport de recherché de la Faculté des Sciences de l'Université de Yaoundé, Cameroun (2007). 